\title{
EFFECT OF THE LCF LOADING CYCLE CHARACTERISTICS ON THE FATIGUE LIFE OF INCONEL 718 AT HIGH TEMPERATURE
}

\author{
F.Taina ${ }^{1,2}$, M. Pasqualon ${ }^{2}$, V. Velay ${ }^{1}$, D.Delagnes ${ }^{1}$, P. Lours ${ }^{1}$. \\ 1-Université de Toulouse \\ Institut Clément Ader \\ Ecole des Mines Albi \\ Campus Jarlard, F-81013 Albi, France \\ 2- Norsk Hydro ASA, Norway.
}

Keywords: LCF, Manson -Coffin, Hold Time, Strain Rate, Load Ratio

\begin{abstract}
A series of both stress-controlled and strain-controlled low cycle fatigue tests were conducted on alloy Inconel 718 to investigate the impact of various parameters on the behaviour of the material. Namely, focus was placed on the influence of major parameters such as the cycle frequency, the strain/stress rate, the holding time at various stress levels, the stress relaxation and the fatigue stress ratio. A detailed characterisation of the fatigue-induced rupture surfaces was performed to analyse the role of the alloy microstructure on the mode of crack propagation. In order to account for the time dependent effect of the mechanical response of the alloy, the Portevin-Le Châtelier effect and the oxidation behaviour of the material are discussed. Results are analysed, in terms of Manson-Coffin plots, to discriminate the relative impact of the various tested parameters on the stress/strain response and the fatigue life of the material.
\end{abstract}

\section{Introduction}

High Temperature low-cycle fatigue materials is a limiting factor in many industrial fields : the related rupture of components is a most common cause of service failure. It is a global problem involving investigations of both metallurgists and mechanical engineers. The development of the applied technology and the increasing demand for high performance structures and components require to work under severe operating conditions, i.e. high stresses, high temperature and variable frequencies.

Inconel 718 is a versatile material that can be employed for different applications where operations at elevated temperature may induce the initiation of fatigue failure.[1]

The detailed understanding of the mechanisms responsible for the fatigue damage is a useful mean to improve the behaviour and the mechanical response of the material subject to cyclic loading. Basically, three factors must be considered to understand fatigue fracture. Namely, the level of the maximum tensile stress, the value of the stress ratio and the number of applied cycles that must be all high enough to provoke detrimental failure. In addition, various parameters either intrinsic, e.g. the composition, the grain and/or precipitate size or extrinsic, i.e. parameters related to the fatigue test may have a strong impact on the fatigue behaviour. [2] 
The aim of the paper is to focus on those test-dependent parameters, in order to emphasize their relative influence on the fatigue behaviour of the material. Tests were conducted at $550^{\circ} \mathrm{C}$, a temperature high enough to provoke detrimental oxidation that can alter the overall mechanical response of the material.

Material

\section{Experimental Procedure}

The weight percent composition of the alloy is reported in table 1:

$\begin{array}{llllllll}\underline{\mathrm{Fe}} & \underline{\mathrm{Cr}} & \underline{\mathrm{Nb}} & \underline{\mathrm{C}} & \underline{\mathrm{Mo}} & \underline{\mathrm{Ni}} & \underline{\mathrm{Al}} & \underline{\mathrm{TI}} \\ 19.0 & 18.0 & 5.20 & 0.04 & 3.0 & \text { Bal. } & 0.50 & 0.90\end{array}$

Table 1. Weight percent (wt \%) composition of Inconel 718.

The material was received in the form of $20 \mathrm{~mm}$ diameter forged bar. The heat treatment consisted of a solution annealing at $955^{\circ} \mathrm{C}$, followed by an air quenching and the usual aging treatments: 8 hours holding at $720^{\circ} \mathrm{C}$, cooling at $50^{\circ} \mathrm{C} / \mathrm{h}$ down to $620^{\circ} \mathrm{C}$ and a final holding at $620^{\circ} \mathrm{C}$ for $8 \mathrm{~h}$. The resulting microstructure is observed in Fig 1: the material shows a small grain size (ASTM 12) and a clear presence of delta phase in the shape of thin platelets preferentially formed on grain boundaries. The precipitation of this phase, due to the segregation of carbides $(\mathrm{NbC}$ or $\mathrm{TiC})$ guarantees the small grain size of the alloy.

Fig 2 shows a typical stress-strain curve at $550^{\circ} \mathrm{C}$ : a Portevin-Le Chatelier (PLC) effect occurs for a strain rate of $10^{-3} \mathrm{~s}^{-1}$. As previously indicated by Garat, the amplitude of PLC stress serrations can be as high as 100 to $200 \mathrm{MPa}$. The interaction between PLC effect and LCF will be investigated in the next sections, especially regarding the strain rate influence on the fatigue behaviour.[3]

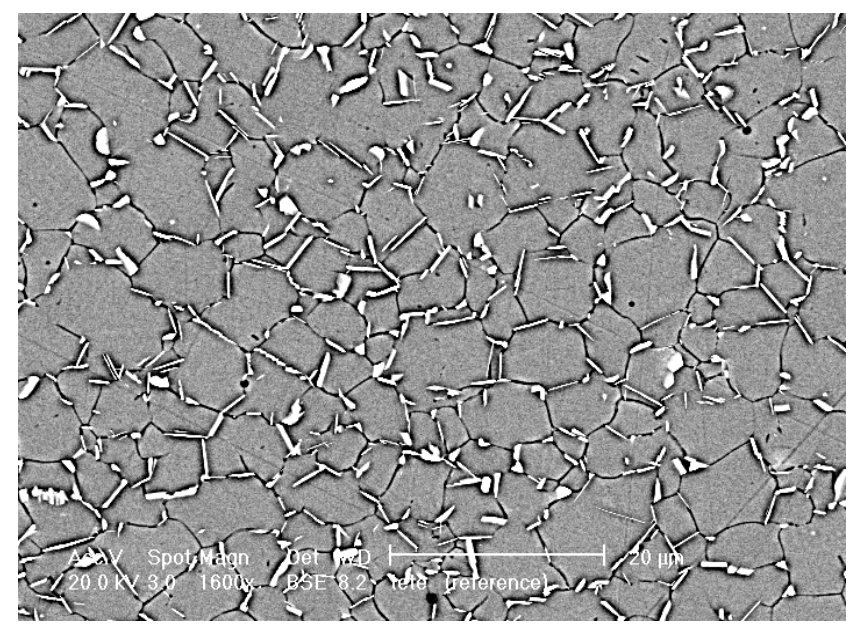

Figure 1. Microstructure of Inconel 718 after conventional heat treatment. 


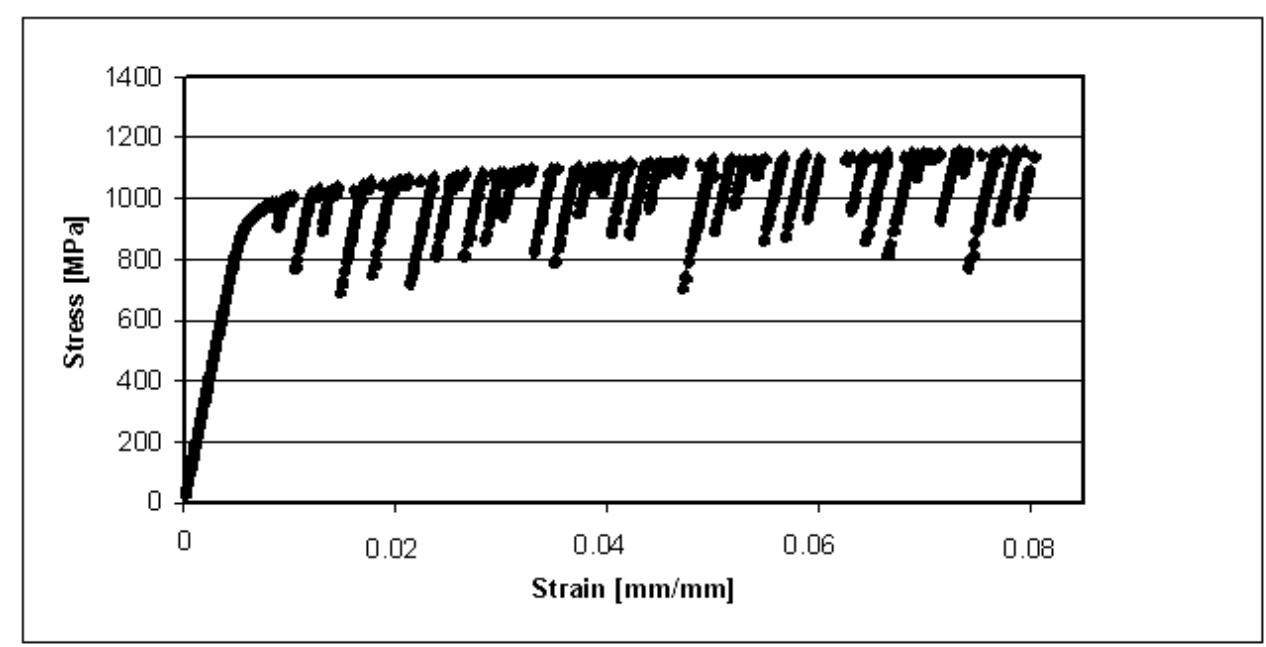

Figure 2. Typical stress-strain relation for a uniaxial tensile test at $550^{\circ} \mathrm{C}$.

\section{Fatigue test}

Isothermal fatigue behaviour of Inconel 718 was investigated at $550^{\circ} \mathrm{C}$ in laboratory air: all tests were conducted using a uni-axial $250 \mathrm{kN}$ Schenck fatigue machine coupled with an induction heating device. The cycle was monitored and measured via a software running on a personal computer. Solid smooth cylindrical specimen with $\Phi=9 \mathrm{~mm}$ diameter and $15 \mathrm{~mm}$ cylindrical calibrated gauge length were used to perform tests. All the specimens were polished to achieve a surface roughness of $\mathrm{R}_{\mathrm{a}}=0.015 \mu \mathrm{m}$. Specimens were induction heated with a Celes high frequency power supply $(2 \mathrm{~kW}, 100-400 \mathrm{kHz})$ : an original water-cooled induction coil was designed and manufactured to ensure uniform temperature along the gauge length and through the cross section of the specimen. Longitudinal, circumferential and radial static thermal gradients over the isothermal gauge were within $15^{\circ} \mathrm{C}, 5^{\circ} \mathrm{C}$ and $5^{\circ} \mathrm{C}$. Thermocouples were not spot-welded on the specimen surface to avoid possible early crack initiation; a flattened K-type thermocouple was half wound around the specimen in centerline. Two types of fatigue tests were performed, respectively in reversed total strain or total stress controlled amplitude conditions:

- $\quad$ Test type one. Total strain amplitude was applied as a triangular symmetrical waveform $(\mathrm{R}=-1)$ and varied according to the following sequence: $\pm 0.6 \%$, $\pm 0.7 \%, \pm 0.8 \%, \pm 0.9 \%$, and $\pm 0.7 \%$, whereas frequency was kept constant at 1 $\mathrm{Hz}$. All tests were run up to failure and the number of cycles was recorded $\left(\mathrm{N}_{\mathrm{f}}\right)$.

- $\quad$ Test type two. Total strain or stress amplitude was applied as a trapezoidal waveform with different stress ratios. All tests were initially run with a strain rate of $5 \cdot 10^{-3} \mathrm{~s}^{-1}$ or a stress rate of $700 \mathrm{MPa} / \mathrm{s}$. Further details about test conditions will be reported in the next sections.

\section{Metallography}

Fracture surfaces were investigated using a scanning electron microscope (SEM). The fatigued microstructure was observed in longitudinal cross-sections of the calibrated gauge length. An electrolytic etching at $2.5 \mathrm{~V}$ potential in a bath containing $10 \mathrm{ml} \mathrm{H}_{2} \mathrm{SO}_{4}$ in $100 \mathrm{ml}$ of water was used to reveal microstructural details. 


\section{Results}

Low cycle fatigue is defined as damage occurring after a limited number of cycles, typically lower than 10,000, as consequence of high stresses resulting in significant plastic strain at each cycle. This type of fatigue must be considered when designing many industrial components, especially when, because of geometrical singularities for instance, high stress can concentrate in specific locations. In order to better understand the fatigue behaviour of Inconel 718 at $550^{\circ} \mathrm{C}$, a series of total strain controlled tests was performed. The basic information on the cyclic stressstrain behaviour was provided in the form of the hysteresis loops, where the plastic strain range, $\Delta \varepsilon_{\mathrm{p}}$, can be determined as maximum loop width.

The most common mode to exploit the LCF test results is to plot the plastic strain range at half life $\Delta \varepsilon_{\mathrm{pl}}$ against the fatigue life $(\mathrm{N})$. This type of relation is known as the Manson-Coffin relation written [4]:

$$
\frac{\Delta \epsilon_{p}}{2}=\epsilon_{f}^{\prime}(2 N)^{c}
$$

where:

- $\Delta \varepsilon_{p} / 2$ is the plastic strain amplitude;

- $\varepsilon_{\mathrm{f}}$ is an empirical constant known as the fatigue ductility coefficient, the failure strain for a single reversal;

- $2 N$ is the number of reversals to failure ( $N$ cycles);

- $\quad c$ is an empirical constant known as the fatigue ductility exponent, commonly ranging from -0.5 to -0.7 for metals.

Figure 3 shows the Manson-Coffin relation relative to "Type one" tests. The slope of the straight line, in a bi-logarithmic plot, is equal to -0.58 , in good agreement with the previous description [5].

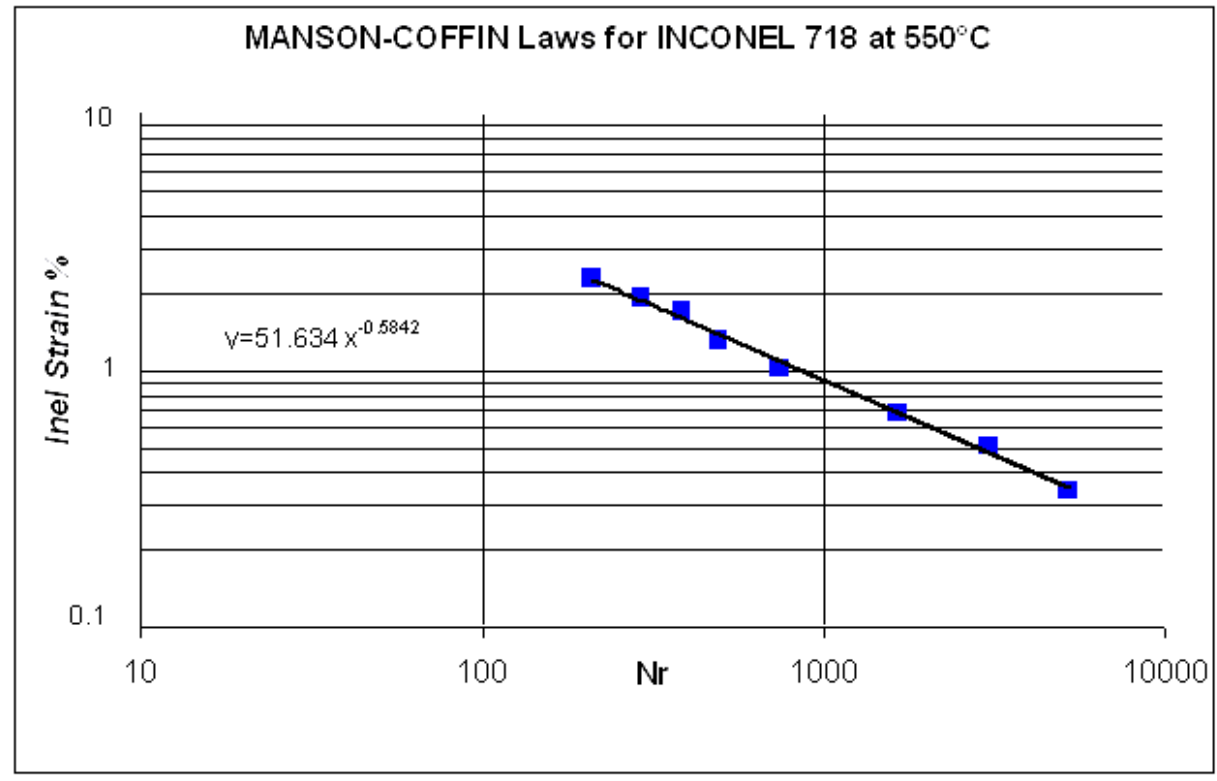

Figure 3. Dependence of fatigue life of Inconel 718 on plastic strain amplitude $\left(\Delta \varepsilon_{\mathrm{p}}\right)$ at $550^{\circ} \mathrm{C}$. 


\section{$\underline{\text { Mechanical Stress-Strain Response }}$}

During fatigue loading, particular transient cyclic phenomenon can occur: depending on the initial state, material can show either full stability, softening or hardening. At $550^{\circ} \mathrm{C}$, Inconel exhibited a sharp softening from the very first cycles as shown in Figure 4, showing the strong decrease of the cyclic tensile stress with the number of cycles for various total strains.

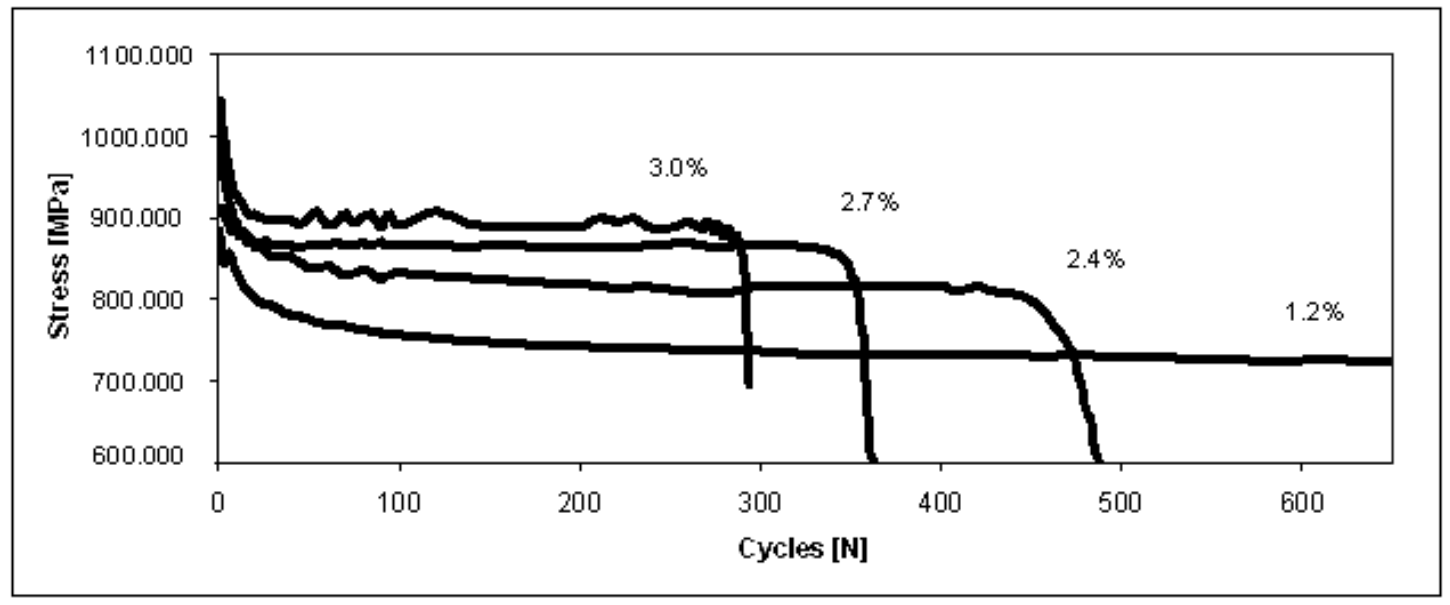

Figure 4. Evolution of the cyclic tensile stress with the number of cycles at $550^{\circ} \mathrm{C}$ as a function of the total strain amplitude.

Based on the cyclic stress curves, three stages may be defined:

- Preliminary softening stage: a severe decrease of the stress occurred during the first 25 cycles, associated to a significant enhancement of the plastic strain amplitude.

- Pseudo-stabilised stage: the plastic strain and stress amplitudes were approximately constant while the material is still continuously deformed along the hysteresis loop. This region of cyclic saturation extended over the major part of the fatigue life.

- Macro-cracking stage: the drop in tensile stress was directly related to the quick propagation of macro-cracks within the monitored gauge length.

Inconel 718 is primarily strengthened by the metastable $\gamma$ " phase precipitates (with dimensions about $30 \mathrm{~nm}$ in diameter and $5 \mathrm{~nm}$ in thickness). Pineau and Clavel [6] have reported that the deformation is mainly due to the propagation of planar bands: under the application of a cyclic stress, the $\gamma$ " precipitates, present in the bands, are continuously sheared by dislocations. As shown by Xiao [7], the process is repeated at each cycle and the size of $\gamma$ " particles is reduced in such extent that they offer very little or no resistance to the dislocations movement. The stress required to shear the smallest particles is reduced, resulting a continuous softening of the alloy and an increase of the strain rate. 


\section{Effect of wave shape on mechanical fatigue}

In industry, materials are usually loaded in complex fatigue conditions including variable holding time under stress/strain, cycle frequency, stress/strain ratio resulting in a wide range of loading wave shape. The impact of those parameters on the materials behaviour is still subject to controversy. Ghonem [8] has studied their influence on the crack propagation; the aim of this paper is to analyse the individual effect of each one on the fatigue life behaviour of Inconel 718.

\section{Effect of holding-time}

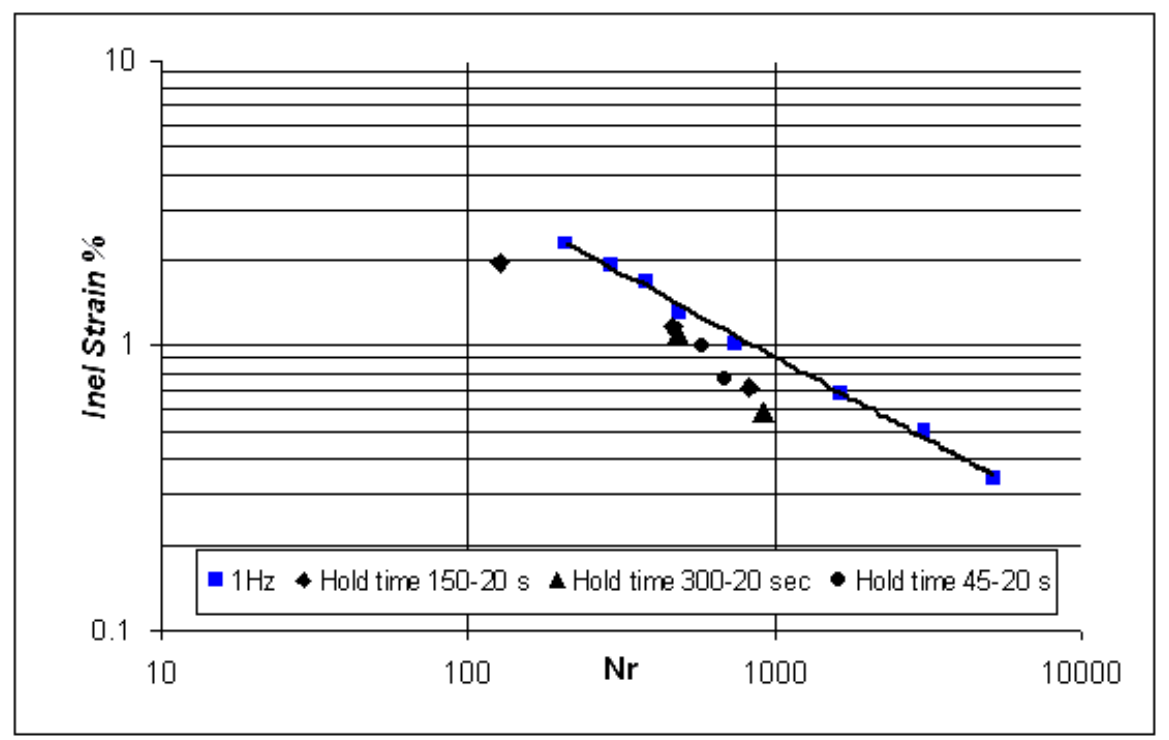

Figure 5. Effect of holding time on fatigue life of Inconel 718 at $550^{\circ} \mathrm{C}$.

Although the effect of the holding time is well defined for fatigue crack propagation, further work is needed to elucidate the mechanisms by which the application of the holding time influences the fatigue life performances. The introduction of holding periods to a low cycle fatigue test at high temperature can be considered as a frequency-related problem, which requires one to investigate the interaction between fatigue and creep, using trapezoidal waveforms. They are defined by the loading times, in seconds, at maximal and minimal strain. For example, 15020 indicates a wave-form with $150 \mathrm{~s}$ at maximal strain and $20 \mathrm{~s}$ at minimal strain. All tests were carried out in total strain controlled mode with an $\mathrm{R}$ ratio equal to -1 and a strain rate of $5 \cdot 10^{-3} \mathrm{~s}^{-1}$. The time spent at minimal compression strain was $20 \mathrm{sec}$ in order to analyse the influence of the holding time in tensile conditions. Figure 5 compares the results obtained by the application of three different wave-forms to the preliminary data obtained with a triangular signal. Holding the material at load results in a significant reduction of the number of cycles to failure. Note that extending the holding time does not decrease further the number of cycle to fracture : all data can be satisfactorily fit, on the Manson-Coffin diagram, along a more or less straight curve below the straight line of $1 \mathrm{~Hz}$ tests.

Figure 6 shows the evolution of the plastic strain amplitude at half life as a function of the total strain. The holding time increased the plastic strain amplitude due to the visco-plastic effects at $550^{\circ} \mathrm{C}$. A possible explanation can be derived considering the holding time effects as a time dependent problem. Indeed, the stress relaxation, occurring at cycle $N$, while holding at constant strain, resulted in a decrease of the material yield strength leading to an increase of the plastic 
strain at cycle $N+1$. This instantaneous process, operating at each cycle, was characterized by a stress drop between 50 and $80 \mathrm{MPa}$ in the hysteresis loops, and produced a global effect that can be noticed by an increase of the plastic strain at half life.

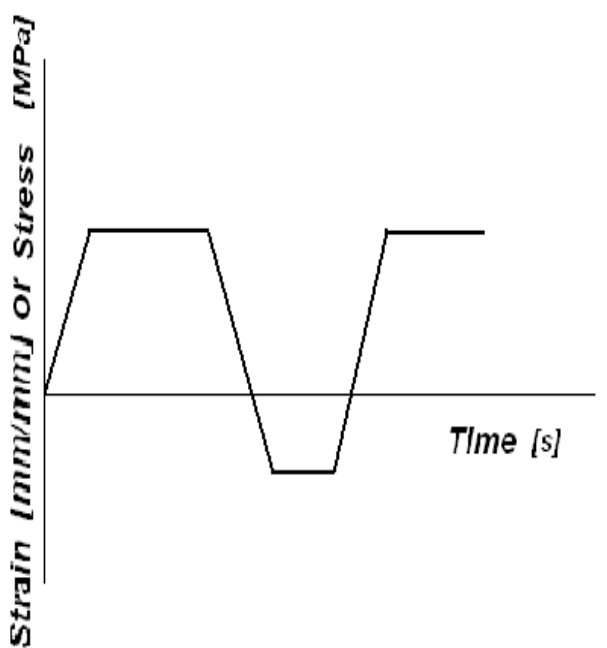

(a)

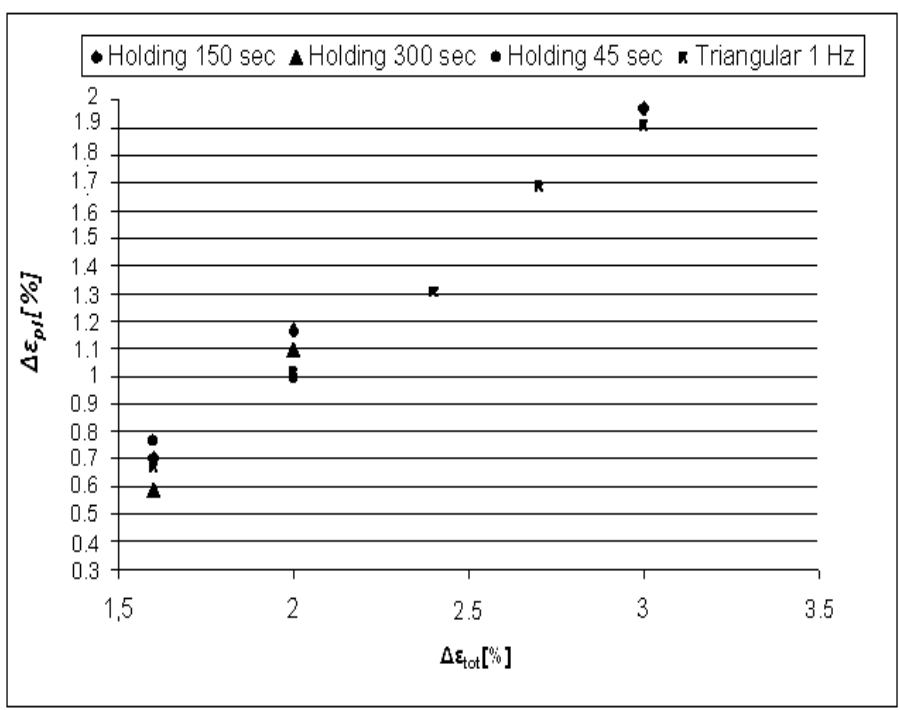

(b)

Figure 6. Schematic representation of the adopted wave shape (Fig.a) and relationship between the total strain and the plastic strain for $\mathrm{LCF}$ test at $550^{\circ} \mathrm{C}$ under triangular signals at $1 \mathrm{~Hz}$ and trapezoidal waveforms (45 s-150 s-300 s holding time) (Fig.b).

\section{Effects of the loading ratio}

The effect of the loading ratio on fatigue life was investigated using stress controlled wave forms with a $150 \mathrm{~s}$ holding time at maximal stress $\left(\sigma_{\text {Max }}\right)$ and $20 \mathrm{~s}$ at minimal stress $\left(\sigma_{\min }\right)$. Three levels of $\sigma_{\mathrm{Max}}$ were tested of 800,1000 and $1100 \mathrm{MPa}$, while $\sigma_{\min }$ varied between -400 and $-900 \mathrm{MPa}$. In the literature, fatigue data are often obtained in conditions of fully reversed stress cycles, $\sigma_{\mathrm{m}}=0$. However, in engineering practice loading usually consists of an alternating stress and a well established mean stress. To take into account these aspects, all fatigue tests may be modelled as a function of the load ratio:

$$
\mathrm{R}=\sigma_{\min /} \sigma_{\mathrm{Max}}
$$

In Figure 7a, fatigue life is plotted against the load ratio, with a particular focus on the maximal stress. For a given $\sigma_{\text {Max }}$, fatigue life increased as the stress ratio or mean stress decreased at constant stress rate $(700 \mathrm{MPa} / \mathrm{s})$. Venkataraman and Nicholas have studied the effect of the load ratio on the fatigue crack growth rate (FCGR). They indicated that in cycle dependent condition, the FCGR increases with a decrease in $\mathrm{R}$ [9]. This is a first indication on how $\mathrm{R}$ influences the material behavior. However, considering the total life as a result of two contributions i.e., the crack initiation and the crack propagation, a higher negative load ratio would involve an important compressive stress in the cycle which increases the amplitude of the hysteresis and enhances the plastic strain $\left(\Delta \varepsilon_{\mathrm{p}}\right)$. This mechanism tends to accelerate the crack initiation. The equation derived by Tanaka and Mura, particularly suitable for crack initiation in Stage I, establishes this dependence [10]. 


$$
N_{i}=\frac{1}{d} \frac{A_{\text {stadzI }}}{\left(\Delta \varepsilon_{p}\right)^{2}}
$$

Where $A_{\text {stadel }}$ is a constant, $d$ is the grain size and $\Delta \varepsilon_{p}$ the amplitude of the plastic strain.

It can be concluded that $\mathrm{R}$ has a direct influence on both the crack initiation and the crack propagation. Figure $7 \mathrm{~b}$ reports the Manson-Coffin relationship expressed for each maximal stress. The fatigue life is strongly influenced by the peak stress. At a constant value of plastic strain, increasing $\sigma_{\text {Max }}$ decreases fatigue life.

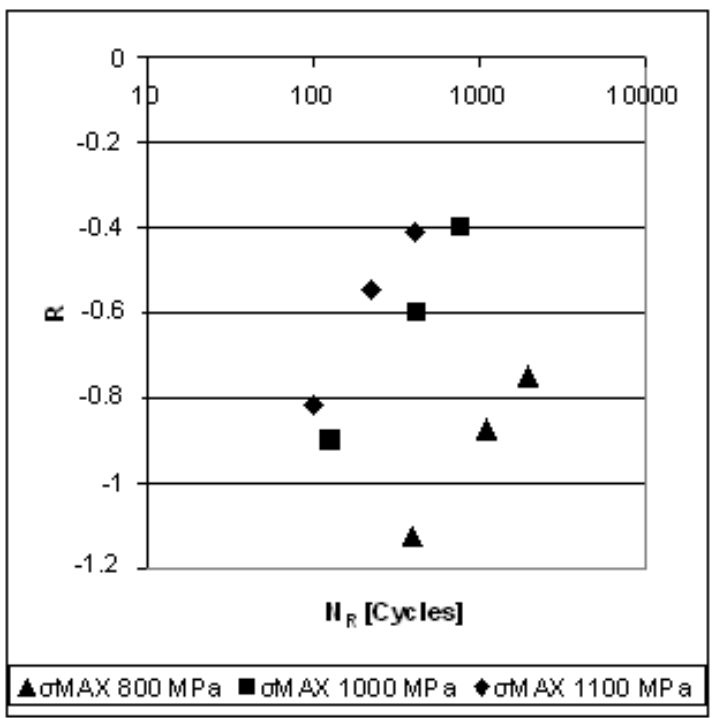

(a)

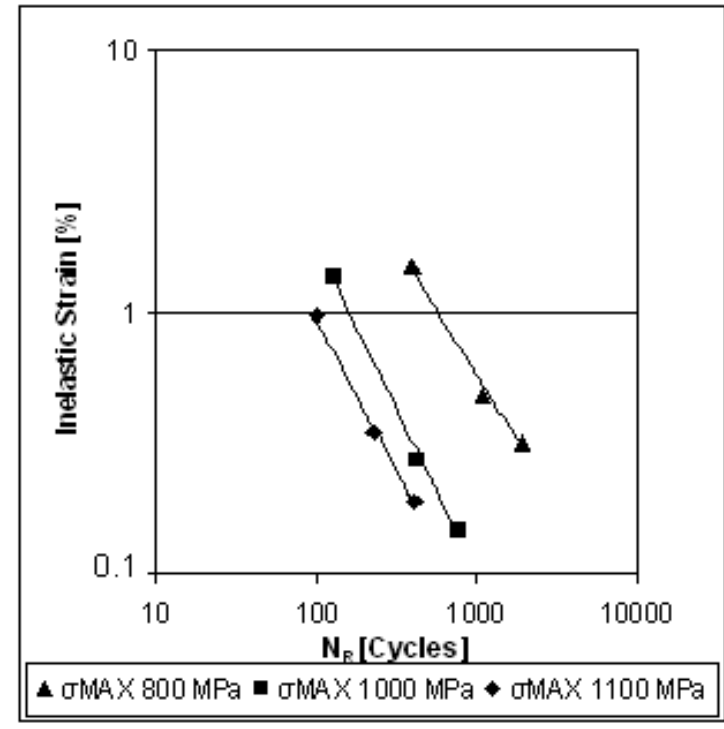

(b)

Figure 7. Fatigue life of Inconel 718 as a function of the load ratio $R$ (Fig.a) and the plastic strain (Fig.b) under stress controlled tests at $550^{\circ} \mathrm{C}$.

For non-symmetrical stress controlled tests, ratcheting clearly occurred (Fig.8). This effect resulted from the accumulation of plastic strain and was illustrated by a continuous shift of the hysteresis loops towards the maximal total strains. Ratcheting is considered a damaging mechanism prone to produce not only detrimental high deformations but also fatigue damage in the material, thus limiting fatigue life. These effects are particularly significant for $\mathrm{R}$ in the range $-0.9 /-0.4$.

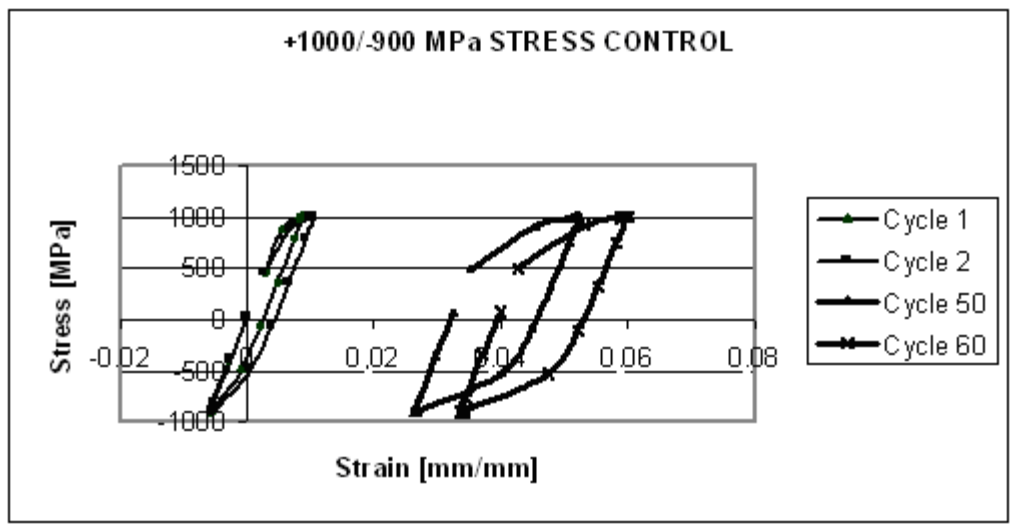

Figure 8. Ratcheting effects in Inconel 718 under stress controlled fatigue tests at $550^{\circ} \mathrm{C}$. 
Effects of strain rate

To study the effect of strain rate on the LCF behaviour, two different strain rates $\left(5 \times 10^{-2} \mathrm{~s}^{-1}\right.$ and $\left.5 \times 10^{-3} \mathrm{~s}^{-1}\right)$ were tested. A total strain controlled $150 \mathrm{~s} / 20 \mathrm{~s}$ trapezoidal signal was used with different strain amplitudes. The test results are detailed in Table 2, showing that a higher strain rate corresponds to a longer fatigue life.

\begin{tabular}{|c|c|c|c|}
\hline Strain rate $\left[\mathrm{s}^{-1}\right]$ & $\begin{array}{c}\text { Total Applied Strain } \\
\Delta \varepsilon_{\text {Tot }}[\%]\end{array}$ & $\begin{array}{c}\text { Number of cycles to } \\
\text { failure }\left(N_{f}\right)\end{array}$ & $\begin{array}{c}\text { Plastic strain at half life } \\
\Delta \varepsilon_{p}[\%]\end{array}$ \\
\hline $5 \times 10^{-3}$ & 3.0 & 127 & 1.97 \\
\hline & 2.4 & 254 & 1.42 \\
\hline & 2.0 & 467 & 1.16 \\
\hline $5 \times 10^{-2}$ & 3.0 & 205 & 1.47 \\
\hline & 2.4 & 381 & 1.12 \\
\hline & 2.0 & 753 & 0.88 \\
\hline
\end{tabular}

Table 2

Results in Table 2 show that the amplitude of the hysteresis loop, indicated by the plastic strain at half life, was reduced when the strain rate increases. Unsurprisingly, this macroscopic mechanical effect has been associated with a microstructure evolution. Kirman and Warrington [11] have reported that the mechanisms of deformation in Inconel 718 induce the formation of stacking faults within the strengthening precipitates $(\gamma$ "). Those faults locally reproduce the crystallographic sequence of the $\delta$ phase.

Clavel and Pineau [12] have proposed a post deformation heat treatment, including a 80 hours holding at $770^{\circ} \mathrm{C}$, prone to enhance the size of the $\delta$ phase nuclei. These precipitates, localised along the slip lines, allow a better observation of the plastic strains less than about $1 \%$.

In Fig. 9 the effects of the post deformation treatment can be appreciated. The $\gamma "=\varnothing$ transformation was utilised to compare the different effects of strain rate. The micrograph in Figure 9a shows the deformation path relative to a slow strain rate. The grains are delineated by a pronounced presence of $\delta$ phase which indicates the occurrence of two activated slip planes. Several slip lines are observed. They are specifically confined within the grains showing an important amount of plastic strain. Fig. 9(b) detailed the deformed microstructure observed for higher strain rate. In this case, the density of slip lines drastically decreases as a consequence of a reduced amount of plasticity. As a conclusion, it can be claimed that a higher strain rate increases the fatigue life of Inconel 718 at $550^{\circ} \mathrm{C}$, as a result of a limitation of the plastic strain produced during the mechanical cycle. 


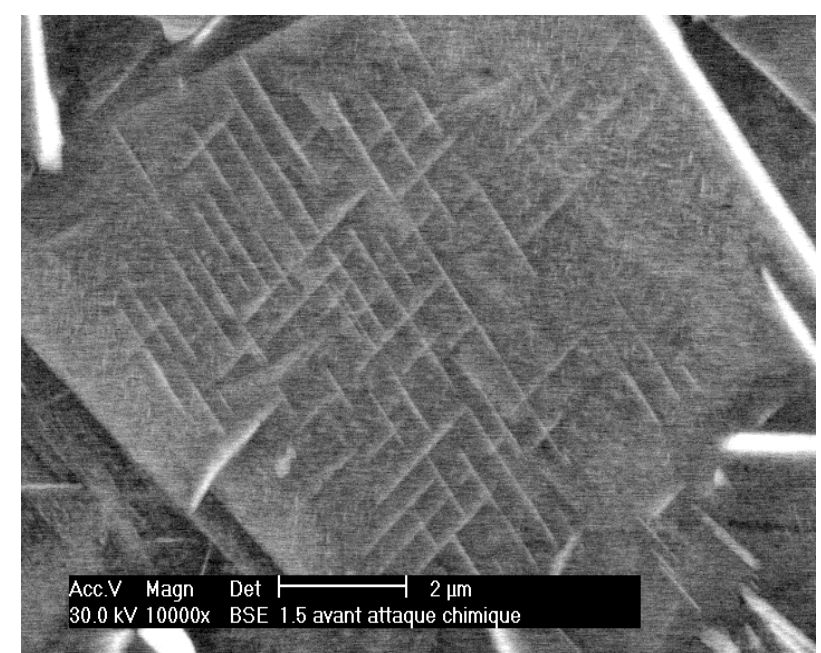

(a)

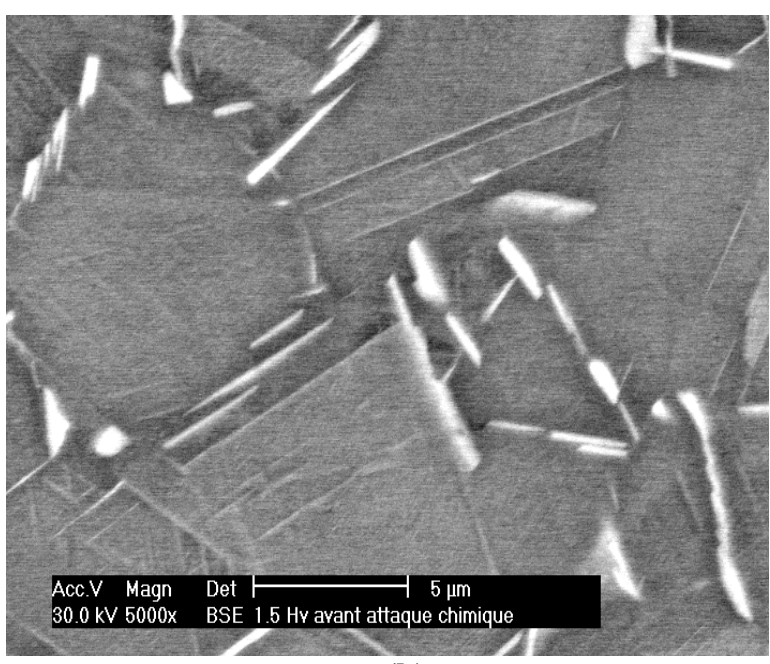

(b)

Fig 9. Comparison of the plastic zones observed under 150s/20s (1.5\% Total applied strain) trapezoidal load at different strain rates: $5 \times 10^{-3} \mathrm{~s}^{-1}$ (a) and $5 \times 10^{-2} \mathrm{~s}^{-1}(\mathrm{~b})$

\section{Fractography}

A detailed examination of the fracture surfaces of the fatigued samples was conducted in order to investigate the different damage stages, that is the crack initiation, the crack propagation and the final catastrophic fracture. Crack initiation was investigated through an accurate observation of the longitudinal cross-sections of each samples. Fig.10 shows the case of a sample loaded using a triangular signal with a strain amplitude of $1.5 \%$. This is a common Stage I initiation site. Pineau [5] showed that this mechanism is closely related to the formation of intense deformation bands formed by twinning which look like the so-called slip-band extrusions. The number of initiation sites was directly proportional to the amplitude of the total strain. Clavel [13] showed that the distance between the deformation bands is strongly dependent on the plasticity rate associated to each cycle.

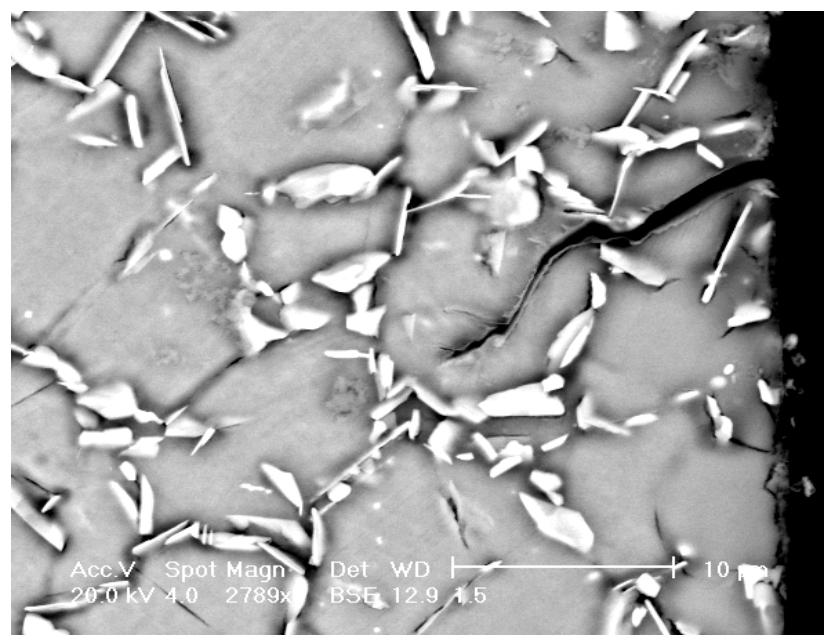

Figure 10. Typical transgranular propagation of a secondary crack under LCF test at $550^{\circ} \mathrm{C}$

The crack propagation is shown in Figure 11, where fatigue striations are clearly revealed on the fracture surface. Fig 11(a) and (b) correspond to the rupture of specimens respectively loaded using a triangular signal and a 150s/20 s trapezoidal wave-form. In both conditions, crack 
propagation was predominantly transgranular. Spacing of fatigue striations increased as the strain ratio increased.
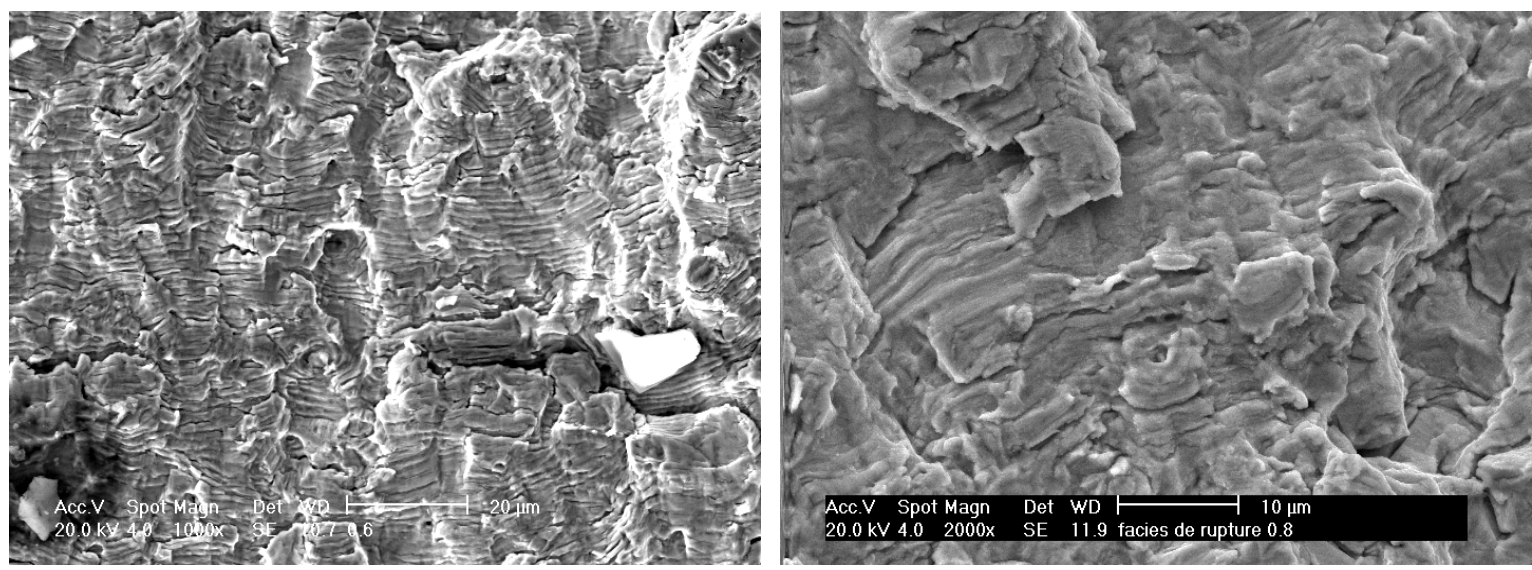

Figure 11. Scanning electron micrographs of fracture surfaces after LCF tests at $550^{\circ} \mathrm{C}$ : triangular signal at $1 \mathrm{~Hz}$ (a) and trapezoidal 150s/20s waveform (b).

The lack of intergranular propagation associated with the trapezoidal wave form may be explained in two different ways:

1. The test temperature $\left(550^{\circ} \mathrm{C}\right)$ was not high enough to provoke strong environmental effects. Even if the equivalent frequency relative to the cycle belongs to a time-dependent domain, the alloy was not sensitive to an oxidation-assisted crack propagation.

2. Garat [3] has shown the occurrence of a particular interaction between the Portevin-Le Chatelier (PLC) effects and the inhibition of the intergranular crack propagation. As a matter of fact, the crack initiation sites and the nucleation zones of strain serrations are located in the same regions of the polycrystal. Strain rate becomes a discriminating factor for the activation of the PLC mechanism. At $550^{\circ} \mathrm{C}$, two regimes are proposed by the author: at very low strain rate (lower than $3 \times 10^{-4} \mathrm{~s}^{-1}$ ) the PLC effects are not activated and the fatigue failure is intergranular, while at high strain rate (higher than $3 \times 10^{-4} \mathrm{~s}^{-1}$ )' strain jumps occur and the failure mode is fully transgranular. In our investigation we considered two strain rates which belong to the second regime and the occurrence of the PLC effect is shown on the stress-strain curve previously reported in section 1 . These results show how the parameters characteristic of the loading cycles, namely the stress/strain rate and the temperature, may be optimized in order to limit the environmental effects and retain high mechanical response of the material.

\section{Conclusions}

The effect of different mechanical parameters on the fatigue life behaviour of Inconel 718 was investigated in details.

The following conclusions can be derived:

- The fatigue life behaviour of Inconel 718 was investigated at high temperature $\left(550^{\circ} \mathrm{C}\right)$. The relationship between plastic strain and fatigue life was modelled using the so-called 
Manson-Coffin relation. A preliminary campaign of fatigue tests was carried out at a frequency of $1 \mathrm{~Hz}$ in order to obtain reference data.

- Fatigue loading generates a particular transient-cyclic process: the alloy showed a clear softening behaviour as soon as the very first cycles were completed, resulting in a decrease of the cyclic tensile stress with the number of cycles.

- The application of a holding time at maximal and minimal stresses provokes an increase of the plastic strain amplitude at half life, reducing the fatigue life of the material. Three different wave forms were employed (45 s, $150 \mathrm{~s}$ and $300 \mathrm{~s}$ ): the increase of the holding time at maximal strain does not further decrease the fatigue life.

- The influence of load ratio was investigated using stress controlled cycles. Fatigue life increases as the stress ratio or the mean stress under constant stress rate $(700 \mathrm{MPa} / \mathrm{s})$ decreases.

- At $550^{\circ} \mathrm{C}$ low cycle fatigue behaviour is strongly influenced by strain rate. It was shown that a higher strain rate may correspond to a longer fatigue life.

- No indications of intergranular failure were observed, even though specimens were loaded using a trapezoidal signal. This result confirms that the service temperature of $550^{\circ} \mathrm{C}$ was not high enough to provoke an oxidation-assisted crack propagation.

\section{References}

1. L. Coffin, "Introduction to High-temperature Low-Cycle Fatigue," Experimental Mechanics, 8 (5) (1968), 218-224.

2. H.J Christ, "Cyclic Stress-Strain Response and Microstructure", Handbook: Fatigue and Fracture, vol.19 (ASM International, 1996), 75-93.

3. V. Garat, J. M. Cloue, D. Poquillon et al., "Influence of Portevin-Le Chatelier effect on Rupture Mode of Alloy 718 Specimens," Journal of Nuclear Materials, 375 (1) (2008), 95-101.

4. D. G. Ellwood, Mechanical Metallurgy, 2nd Edition (McGraw-Hill, 1976), 350.

5. D. Fournier, and A. Pineau, "Low Fatigue Cycle Behaviour of Inconel 718 at $293 \mathrm{~K}$ and 823 K," Metallurgical Transactions A-Physical Metallurgy and Materials Science, 8 (7) (1977), 1095-1105.

6. M. Clavel, and A. Pineau, "Frequency and Wave-Form Effects on the Fatigue Crack Growth Behaviour of Alloy 718 at $298 \mathrm{~K}$ and $823 \mathrm{~K}$," Metallurgical and Materials Transactions A, 9 (4) (1978), 471-480.

7. L. Xiao, D. L. Chen, and M. C. Chaturvedi, "Cyclic Deformation Mechanisms of Precipitation-Hardened Inconel 718 Superalloy," Materials Science and Engineering: A, vol. 483-484 (2008), 369-372.

8. H. Ghonem, T. Nicholas, and A. Pineau, "Effects of Environmental and Material Variables " Fatigue \& Fracture of Engineering Materials \& Structures, 16 (6) (1993), 577-590. 
9. H. Ghonem, T. Nicholas, and A. Pineau, "Elevated-Temperature Fatigue-Crack Growth in Alloy 718-Part 1: Effects of Mechanical Variables," Fatigue \& Fracture of Engineering Materials \& Structures, 16 (5) (1993), 565-576.

10. F. Alexandre, Probabilistic and Microstructure Aspects of Crack Initiation in Alloy 718, (Paris, Ecole des Mines de Paris, 2004), 66.

11. I. Kirman, and D. Warrington, "The Precipitation of Ni3Nb Phases in a $\mathrm{Ni}-\mathrm{Fe}-\mathrm{Cr}-\mathrm{Nb}$ Alloy," Metallurgical and Materials Transactions B, 1 (10) (1970), 2667-2675.

12. M. Clavel, D. Fournier, and A. Pineau, "Plastic Zone Sizes in Fatigued Specimens of Inconel 718," Metallurgical Transactions a-Physical Metallurgy and Materials Science, 6 (12) (1975), 2305-2307.

13. M. Clavel, and A. Pineau, "Fatigue Behaviour of two Nickel Base Alloys I: Experimental Results on Low-Cycle Fatigue Crack Propagation and Substructures," Materials Science and Engineering, 55 (2) (1982), 157-171. 